\title{
Fronteira entre análise de discurso e semântica histórica da enunciação: abordagens teóricas
}

Boundary between discourse analysis and historical semantic of enunciation: theoretical approaches

\author{
Fabiana Fernanda Steigenberger \\ Faculdade de Jandaia do Sul - FAFIJAN/PR \\ Julio Cesar Machado \\ Fundação do Ensino Superior de Passos - FESP/UEMG \\ Soeli Schreiber da Silva \\ Unicamp
}

Resumo

Este artigo traz para o espaço científico um enunciado do espaço informal: "Análise de Discurso (AD) e Semântica Histórica da Enunciação (SHE) não parecem ser a mesma coisa?". Muito além de apenas uma asseveração ingênua e desavisada, podemos vislumbrar nesse enunciado um quadro de pesquisadores agenciados por essa incógnita que orienta para uma prática de pesquisa caótica, em que o uso indevido e invertido de aparato teórico de uma teoria no interior da outra acaba por produzir efeitos de miscelânea científica. Desvelamos uma prática involuntária de "trapacear com a ciência" ao unificar dois campos teóricos, tornando, por isso, este artigo digno de atenção. Para tal determinamos como objeto alguns dispositivos de análise presentes na $\mathrm{AD}$ e na SHE com o propósito de traçar um paralelo entre eles e identificar possíveis proximidades e distanciamentos. 


\section{Palavras-Chave}

Análise do Discurso, Semântica Histórica da Enunciação, Discurso, Acontecimento, Sujeito, Cena enunciativa.

\section{Abstract}

This article brings to scientific inquiry a statement about informal space: "Does it mean that Discourse Analysis (DA) and Historical Semantics of Enunciation (HSE) are the same thing?" Much more than just a naive and unsuspecting assertion, we can see that researchers stymied by this unknown that leads to chaotic research practice, in which the misuse and inverted theoretical apparatus of one theory inside the other, ends up producing miscellaneous scientific effects. We reveal an involuntary practice of "cheating with science" by unifying two theoretical fields, making this article therefore worthy of attention. We selected as the object some devices of analysis present in DA and HSE for the purpose of drawing a parallel between them and identifying possible nearness and distance.

\section{Keywords}

Discourse Analysis, Historical Semantic of Enunciation, Speech, Event, Subject, Enunciative scene. 


\section{A prática teórica da Linguística}

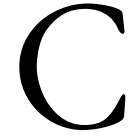

onforme explica Benveniste (2006), a Linguística é uma ciência que busca "transformar as palavras que voam em uma matéria concreta, que se estuda, que se disseca, onde se delimitam unidades, onde se isolam níveis (BENVENISTE, 2006, p. 29). O nome disso é teoria. O que possibilita a concretude e análise de certa matéria é a chamada teoria. Nosso foco, portanto, não será "a teoria”, senão a convergência / divergência "de teorias". O plural dessa concretude e dissecamento benvenistiano torna-se um panorama peculiar de prática científica plural e por vezes, um labirinto de fauno. As teorias esbarramse, respeitam-se, digladiam-se, mas todas elas vão tecendo a malha heterogênea da Linguística.

No interior desse quadro heterogêneo queremos atentar-nos para certo fenômeno comum de todo analista. Quase que um procedimento involuntário: a comparação entre teorias que parecem próximas. É claro que a comparação é uma metodologia didática de longa data, com pertinências razoáveis devido à facilidade e eficácia na assimilação entre comparada/comparante. Mas em se tratando de Linguística, comparações entre teorias devem basear-se em razões metodológicas ou analíticas. A mera disposição de uma teoria com outra, focando uma eleição de primor, é um tanto que utópica e desnecessária.

É comum, no meio didático, certo professor assumir uma postura teórica e, por meio dela, depreciar posturas teóricas vizinhas (de modo que seus discentes acabem por serem seus prosélitos).

É uma situação delicada: admitamos a inevitável condição de fazer-se sujeito de uma teoria, para a prática acadêmica/Linguística. Mas um posicionamento maduro deve considerar o seu redor. E lidar com teorias distintas requer não apenas o conhecimento de ambas ou a assunção de uma. A "super teoria", a "teoria heroína" não logra cientificidade, senão que não passa de narcisismo linguístico (GADET; PÊCHEUX, 2004). 
Portar-se em um quadro pluriteórico reclama o requinte de uma descrição em que esse mesmo nó converge: se se fala em distintividade, o que se leva a sustentar essa distintividade? Por que não cair na sedução de uma unicidade teórica, tão conveniente à prática didática? Quais processos e condiçôes postulam a perpetuação da pluralidade, ao invés de objetá-la?

\section{A comparação como metodologia para a desconstrução da semelhança}

O pressuposto básico de que "não há teoria perfeita", pelo mesmo motivo de que não há consenso no que seja o objeto da Linguística (MARCUSCHI, 2008), autoriza-nos a dizer que sopesar relevâncias de teorias $X$ em relação a teorias $Y$ são razoáveis apenas em certas circunstâncias específicas. E este artigo quer levantar uma delas: a desconstrução da semelhança entre dois campos do saber: a Análise de Discurso de linha francesa (doravante AD) e a Semântica Histórica da Enunciação (doravante SHE), confundidas devido à ampla circulação da primeira, no Brasil, ou à prática da segunda por integrantes da primeira, ou à execução das duas em eventos próprios de só uma delas, entre outros.

O que dificulta sobremaneira a distinção entre ambas é o quadro científico de que não só as teorias mas os seus praticantes estão em constante diálogo. Portanto, na prática, o efeito de semelhança passa a ser constante, a visitação de noçôes entre elas, frequente, e a distinção entre ambas, reservada para lentes mais aguçadas.

Contrariando o raciocínio amador, asseveramos que semelhança não justifica unificação. A superficialidade da semelhança não se sustenta diante da cientificidade específica. Segundo Benveniste, "toda disciplina que visa adquirir o estatuto de ciência deve inicialmente definir suas constantes e variáveis, suas operações e seus postulados, e antes de tudo dizer quais são suas unidades" (BENVENISTE, 2006, p. 224). Assim, se as constantes, operaçōes, variáveis e unidades são distintas, semelhança não significa consonância. E ao relevar esses quesitos é bom acentuar que, se uma teoria X "constrói" seu objeto conforme seus pressupostos, do mesmo modo, uma teoria $Y$ "construirá” seu objeto também por seus outros pressupostos.

A primeira questão que se põe é: se o objeto da teoria X é, por exemplo, a "língua", e se o objeto da teoria $Y$ também é a "língua", estamos diante de duas linguas diferentes se os mecanismos teóricos mostram-se diferentes, uma vez que se está diante de dois planos que "[...] dependem senão de métodos, ao menos de idéias 
epistemológicas ou metodológicas distintas" (PIGUET apud BENVENISTE, 2006, p. 239).

Se assim não o fosse, não teríamos a beleza eclética dos objetos "língua", que perfazem o mosaico da Linguística: a língua como sistema (BALLY; SECHEHAYE, 1995), a língua como gramática hereditária (CHOMSKY, 1998), a língua como ação (AUSTIN, 1962), a língua como argumento (DUCROT, 1987), a língua como ideologia (ALTHUSSER, 1998), a língua como função (JAKOBSON, 2005), a língua como estratificação axiológica (BAKHTIN, 2004), a língua como subjetivação (BENVENISTE, 2006), até a incrível afirmação de que "não existe língua" (AUROX, 1998). E finalmente, dentre tantas outras definições nossos dois alvos: a língua como discurso própria da AD (PÊCHEUX, 1997) e a língua como possibilidade de enunciação, própria da SHE (GUIMARÃES, 2002).

Ao lado dessa vasta conceitologia heterogênea de definições sobre a língua, ainda temos de considerar as diferentes noçōes de sujeito a elas atreladas, pois cada concepção de língua adota uma visão de sujeito da linguagem. A partir dessa localização já podemos aprofundar nossa proposta analítica de aproximar / distanciar AD e SHE, cientes de que temos duas teorias ladeadas (SCHREIBER DA SILVA, 2004), perscrutando suas constitutividades e seus objetos distintos.

\section{Metodologia: "A Semântica Histórica da Enunciação não se parece demais com a Análise de Discurso?"}

Todo esse prefácio necessário nos situa e remete a um quadro que, na verdade, nos agenciou a explorar as indagações deste artigo. Trata-se de enunciados que circulam repetidamente nos espaços acadêmicos, eventos e aulas em que se postula, analisa ou ensina $\mathrm{AD}$ e $\mathrm{SHE}$, e que nos instiga a refletir sobre ele. Metodologicamente, tais enunciados norteiam este artigo. Esses, enunciados são sempre proferidos nos subespaços informais, "nos bastidores": "a Semântica Histórica da Enunciação não épor demais parecida com a Análise de Discurso"? Ou "A Análise de Discurso e a Semântica Histórica da Enunciação não são na verdade distintas metodologias sobre o discurso?". "A AD e a Semântica do Acontecimento são a mesma coisa? E ainda "Nossa, é tão igual, não é?", entre tantas outras paráfrases. Algumas até mais agressivas, próprias de espaços informais (mas que não deixam de produzir análises pertinentes), preferimos omitir para manter uma cadência acadêmica de polidez. E é isto que, não raras vezes, vemos acontecer em alguns 
eventos à guisa de desavisamento: desconhecimento de filiaçōes epistemológicas, ingenuidade acadêmica, "narcisismo linguístico", como já dito, superficialidade de norte.

Qualquer pesquisador atento não daria ouvido a essas indagações superficiais, por motivos óbvios. Contudo, daremos relevo a essa questão porque dela derivam alguns acontecimentos graves (o que reclama uma pesquisa com a eleição desse tema correlacional): 1) Executar uma das duas teorias determinado por essa incógnita interfere decisivamente no objeto / análise / conclusão. 2) Ler pesquisas, em uma das duas vertentes, tratando-as como sinônimas, acarreta resultados contrários. É o início de um caos linguístico que se instala em certas cenas analíticas, as quais tentaremos ponderar a partir de uma metodologia que nos leva a refletir sobre esses dois pontos teoricamente.

A presente pesquisa não significa um acontecimento desconfortável, porque nosso alvo não constitui um reforço unilateral para-político (RANCIÈRE, 1996) ou seu oposto meta-político entre teorias, com cunho partidário, que culminem em uma "solução" arqui-política. ${ }^{1}$ Como nosso foco é comparatistadesconstrutivista, trazemos para o âmbito formal (científico) enunciados do espaço informal (não científico). Metodologicamente, fazemos do objeto não científico um objeto científico, ao considerar que ambos os espaços - formal e informal - são habitados pelos mesmos locutores. Um sujeito enuncia como pesquisador especialista, no primeiro espaço formal acadêmico, onde a pergunta não procede. Mesmo que ela insista no silêncio (ORLANDI, 2007), deve-se fazer de conta que não se a tem. E o mesmo sujeito enuncia como que perturbado pela incógnita, no espaço informal, onde o efeito de dúvida não transgride as regularidades da cena. Este é o espaço que permite a indiscrição dessa indagação (semelhança entre AD e SHE) e suas petulâncias comparativas. Sobre esse quadro atrever-nos-emos a dar atenção.

\section{A noção de "inconsistência científica"}

Para efetivar a metodologia supra-mencionada pensamos ser fundamental inserir em nossa reflexão a noção de inconsistência cientifica, para melhor operar nossos dados. Com essa noção é possível investigar uma inconsistência que compromete a pesquisa, devido a dois procedimentos equivocados do pesquisador despreparado (aquele que se indaga sobre a semelhança entre AD e SHE ou que 
as tem por sinônimas): o pesquisador em dúvida inevitavelmente irá operar mecanismos da AD na SHE e da SHE na AD, ou ainda, o pesquisador desavisado explicitará uma discrepância caótica aos olhares clínico-linguísticos de linguisticas mais sapientes, ao proceder o modo de raciocínio da AD no interior da SHE e, contrariamente, ao raciocinar pelo prisma da SHE no interior da AD.

Ora, se os que praticam $\mathrm{AD}$ ou $\mathrm{SHE}$, ou até as duas, são os mesmos que enunciam enunciados como "elas não são parecidas demais?/elas não são sinônimas?", não é difícil parafrasear suas performances científicas como "afinal, eu procedo minha análise como se as duas fossem sinônimas", mesmo que indireta e transversalmente. E a inconsistência de posicionamento teórico desses pesquisadores compromete decisivamente sua pesquisa. Orlandi (2008) advertiu que essa prática equivocada não rara é o mesmo que trapacear com a ciência:

O que se vê muito por aí é uma trapaça. Pega-se noções de uma teoria, e quando ela não dá mais conta da análise, vai-se em outra teoria e simplesmente pega-se uma noção dali. E assim por diante, se ainda falta tratamento no corpus, vou indo a outras teorias e colecionando noçôes. Isso é trapacear com a ciência. Uma miscelânea teórica (ORLANDI, 2008, s.p.).

Essa noção de inconsistência científica advém dessa citação e tem lugar basilar neste trabalho porque é ela quem instaurará o rigor necessário para que não se caia na ingenuidade homogeneizante. Ela nos leva a considerar que a Línguística do século XXI, especificamente a produção científica (e os distintos objetivos dessas produçôes) é determinada por um rigor que acaba por agenciar a secção entre esses dois campos: $\mathrm{AD}$ e SHE. É necessária uma cisão teoricamente bem construída. Não dominar essas duas teorias, conforme Orlandi, é "pensar estar produzindo ciência” (efeito imaginário), enquanto na verdade, determinado pelas condições linguísticas de equívoco atuais, é "estar praticando inconsistência científica” (efeito de real). Não é uma questão de exagero ou excesso de cuidado, mas uma questão de sutileza que a cientificidade exige. Uma divisa delicada, que acarreta a latência de suas violações. 


\section{Diferentes objetos, equivocidade analítica e comprometimento de conclusão ${ }^{2}$}

É fato que Pêcheux abriu uma porta diferenciada, inteligente, para os estudos sobre a linguagem (SERIOT, 2011). Desde então a AD desenvolveuse em larga escala. E a SHE, embora não se ramifique nela, dela aprendeu a tratar o sentido por vias "alinguísticas" ou históricas. Contudo, trazer Pêcheux por empréstimo para a SHE não significa de modo algum trazer a $\mathrm{AD}$ para a enunciação. Julgamos essencial uma distinção bem pormenorizada, pois como na reflexão dos outros autores, deslocar o modo de raciocínio de um outro campo teórico acarreta certas reescrituras e requer algumas consideraçōes.

A SHE mantém relações estreitas com a $\mathrm{AD}$ pela partilha de alguns conceitos. Embora alguns dos procedimentos de ambas, à primeira vista, atestem um certo efeito de sinonímia, essa suposta sinonímia é logo desfeita quando da consideração crucial de seus objetos de trabalho: o objeto da $\mathrm{AD}$ é o discurso e o objeto da SHE é a enunciação. Mesmo pela ingênua unificação de alguns autores, para nós constituem-se dois objetos distintos.

Ao trabalhar entre teorias vizinhas, a falta de cuidado da não distinção desses dois objetos de estudo (enunciação e discurso) pode acarretar o infortúnio da ilusão de objeto de estudo VERSUS realização analítica e comprometer a conclusão. Esta seção quer otimizar esse cuidado e aliviar a tensão da constituição de nosso objeto. Qual seria então essa relação entre os objetos dos campos de saber da SHE e da AD?

\section{Aproximações e distinções entre SHE e AD}

No que tange à aproximação, diremos que existe uma relação distinta de seus objetos, mas dialógica, entre as duas disciplinas. Isso não pode ser confundido com relação de antonímia, mas de completude, marcada principalmente por noções da $\mathrm{AD}$ como alíngua, incompletude, condiçôes de produção e interpretação, dentre outras, que, apesar de estrutura homônima, são determinadas por posições teóricas e metodológicas distintas (SCHREIBER DA SILVA, 2004, p. 2).

No que tange à separação, embora de boa convivência, as duas disciplinas mantêm orientaçōes opostas. Considerada a dicotomia moderna sistema / execução (que rememora langue / parole), dispõe-se este horizonte de futuridade: 
(1) A Semântica Histórica da Enunciação produz sentidos sopesando as perspectivas sócio-históricas $N A$ enunciação.

[...] o sentido não está na língua, mas no funcionamento [...] a significação das frases é definida pelo que as palavras acabam por significar em virtude do funcionamento da língua segundo as condições históricas em que este acontecimento (do funcionamento da língua) se dá. (GUIMARÃES, 2007, p. 117, grifo nosso).

Assim:

SHE [funcionamento (sócio-histórico)]—-) efeito de sentido. ${ }^{3}$

(2) A AD pecheutiana, ao contrário, identifica sentidos antevendo o funcionamento enunciativo $N A$ ideologia.

a discursividade não é a fala (parole) [...] não se trata de um uso, de uma utilização ou da realização de uma função. Muito pelo contrário, a expressão processo discursivo visa explicitamente a recolocar em seu lugar (idealista) a noção de fala (parole). [...] o sentido existe exclusivamente nas relações de metáfora [...] das quais certa formação discursiva vem a ser historicamente o lugar mais ou menos provisório (PÊCHEUX, 2009, p. 82, 240, grifo nosso).

Assim:

$\operatorname{AD}\{[$ fala(discursividade) $]-)$ ideologia $\}-)$ efeito de sentido. ${ }^{4}$

Conforme os dois recortes, na SHE, lingua dispõe-se como "antonímia” de sentido ("o sentido não está na língua") e sentido determina funcionamento ("o sentido não está na língua, mas no funcionamento"). Já na $\mathrm{AD}$, discursividade dispõe-se como "antonímia" de fala ("a discursividade não é a fala"), e processo discursivo reescreve por "substituição" discursividade, significando-a sinonimicamente (processo discursivo - discursividade), e ambas são determinadas pela ideologia ("processo discursivo quer recolocar em seu lugar (idealista) a noção de fala"). Temos o DSD: 5 
\begin{tabular}{c|c|} 
SHE: & Sentido $-\mid$ funcionamento \\
\cline { 2 - 2 } & língua \\
\hline
\end{tabular}

Figura 1
AD:

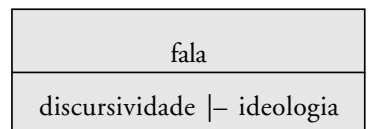

Figura 2

É obvio que não precisaríamos dizer (mas mesmo assim o fazemos) que a ciência não se estabiliza, ainda mais de um ponto de vista político como o nosso. Estamos cientes de que, ao considerar a vasta produção e enorme gama intelectual das duas disciplinas ( $\mathrm{SHE}$ e $\mathrm{AD}$ ), a antonímia desses dois quadros está propensa a inversões, determinações, mutações diversas, ramificações, movimentos, determinações uma da outra etc. Contudo, esses DSDs vislumbram um princípio, o foco do objeto de estudo dos dois saberes. Não é um DSD de fechamento ou de uma totalidade de obras. É um DSD basilar inicial, próprio para fins correlacionais aqui pretendidos, que almeja pontuar distinções entre SHE e AD. Uma disposição inicial de DSD das duas disciplinas por continuar...

Além disso, a partir desses dois trechos escolhidos, podemos ainda fazer outra dupla leitura dos dois saberes, que também os une e os separa. A primeira, baseada nas palavras históricas (SHE) e historicamente (AD), que determinam o sentido. Assim:

(3) $\mathrm{O}$ que une SHE e AD:

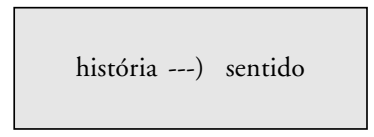

Figura 3

E a segunda, se observarmos de perto os trechos: "o sentido não está na língua, mas no funcionamento" (da SHE) e "a discursividade não é a fala (parole) [...] não se trata de um uso, de uma utilização" (da $\mathrm{AD}$ ), vemos bem que os dois saberes marcam a divisão língua / fala (ou uso, funcionamento, utilização etc), como também é claro que cada um dos dois saberes prioriza um foco de análise, sem desprezar, todavia, o outro: a $\mathrm{AD}$ atenta-se para o caráter discursivo da língua, mesmo se relacionado com a fala, e a SHE atenta-se para o caráter da fala (o funcionamento), mesmo se relacionado com a língua. $\mathrm{O}$ que revela uma antonímia teórica fundamental:

(4) O que separa SHE da AD:

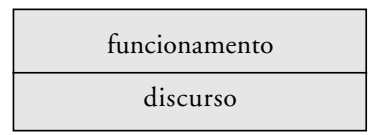

Figura 4 
É claro que, por vezes, ambas SHE e AD abordam as noções de enunciação e discursividade, uma vez que seria por demais imaturo pensar a linguagem disposta a exclusōes radicais. Contudo, ao fazê-la, não se deve cair na ingenuidade de pensá-las igualmente, uma vez que a $\mathrm{AD}$ pensa a enunciação determinada pela contingência discursiva. Seria uma possibilidade de enunciação determinada pela discursividade (foca-se mais o discurso que a própria enunciação), enquanto que a SHE, quando fala em discursividade, o faz relacionando-a ao acontecimento enunciativo. Seria a possibilidade da discursividade determinada pela enunciação (foca-se mais o funcionamento e suas feiçōes que a virtualidade de um discurso). As determinaçôes constitutivas dos dois saberes baseiam-se fundamentalmente na organização de que a $\mathrm{AD}$ é do campo da disposiçāo da língua que vislumbra sujeito e história; e a SHE é do campo da execução da língua que instaura os mesmos sujeito e história. E é claro que um pode e fala do outro. A distintividade é uma perspectiva situacional, que não condena o diálogo.

Temos, então, na relação entre $\mathrm{SHE}$ e $\mathrm{AD}$, uma diferença de objeto (discurso / enunciação) que as fazem dialogar. Se a SHE se aproxima da AD pela historicidade, separa-se dela pelo seu objeto de estudo - a enunciação. Ou seja, é uma distinção básica: a $\mathrm{AD}$ investiga o discurso (mesmo que, para isso, fale em enunciação), e a SHE investiga a enunciação (mesmo que, para isso, fale em discurso). Se, portanto, por um lado o pressuposto básico da historicidade as une, por outro lado seus objetos distintos acarretam compromissos teóricos e metodológicos diferentes (SCHREIBER DA SILVA, 2009).

\section{A noção de acontecimento discursivo e seu efeito anafórico (AD)}

É bom que se diga, antes de mais nada, que traçar uma discussão do porte que aqui pretendemos (isolar / relacionar / determinar etc duas vertentes teóricas) pressupóe que nosso leitor tenha um conhecimento mínimo a respeito das teorias aqui comparadas. Sem esse pressuposto prévio a discussão poderia ficar por demais abstrata e vaga. Pressupondo esse conhecimento básico, vamos a elas.

O diálogo entre AD e SHE também pode ser entendido a partir da noção de acontecimento, através da reescrita por substituição da relação anafórica / catafórica. Segundo Schreiber da Silva (2009), o acontecimento da AD sempre "já começou antes, em algum lugar", portanto desencadeia um efeito anafórico, anterior. Assim, baseado em muitos trabalhos de AD, como Pêcheux (1990), 
Guilhaumou; Maldidier (1997), Orlandi (1996), diremos que, para apreendermos de modo geral os efeitos do acontecimento da $\mathrm{AD}$, usaremos a palavra anáfora para condensar noçôes que constituem o a priori $\mathrm{da} \mathrm{AD}$, por serem determinadas por um passado: a memória discursiva, o já-dito.

$\mathrm{Na} \mathrm{AD}$ o acontecimento "[...] é apreendido na consistência de enunciados que se entrecruzam em um dado momento" (GUILHAUMOU, MALDIDIER, 1997, p. 166). Dentro desse arcabouço teórico, para trabalhar com o discurso é necessário pensar o acontecimento, o qual é produzido como "efeito de e em uma dispersão material". Foucault, por meio da noção de acontecimento, reafirma a existência simultânea da regularidade e da casualidade no discurso: a regularidade define uma série discursiva e o acontecimento a dispersa. Pêcheux ressalta que o acontecimento pode ser estudado em seu contexto de atualidade e, ainda, em um espaço de memória que, em seu surgimento, o próprio acontecimento retoma. A memória é reorganizada pelo acontecimento, a qual demonstra um efeito de evidência (um dizer que, naquele determinado momento, não pode ser outro) e, também, é extremamente opaca, por ter em seu bojo práticas discursivas anteriores que possibilitaram seu aparecimento ou buscaram impedir seu surgimento. Acontecimento seria o "ponto de encontro" entre atualidade e memória. Pêcheux afirma que

A partir do exemplo de um acontecimento... a questão teórica que coloco é, pois, a do estatuto das discursividades que trabalham um acontecimento, entrecruzando proposições de aparência logicamente estável, suscetíveis de resposta unívoca (é sim ou não, é x ou y etc.) e formulações irrremediavelmente equívocas (1990, p. 28).

O acontecimento desencadeia o deslocamento de um enunciado produzido em outro lugar, fazendo surgir sentidos outros, ressignificando-o ou viabilizando a produção contínua de paráfrases. Portanto, move o processo de desestruturaçãoreestruturação das redes e trajetos do discurso. $\mathrm{O}$ acontecimento na $\mathrm{AD}$ mostra que o discurso não é uma significação já dada, já-lá, mas que, a partir de um jálá, há sempre a possibilidade de um novo dizer a ser formulado. Termos como "outro lugar", "já-lá", "memória", "história", entre outros, nos permitem dizer que a $\mathrm{AD}$ trabalha por meio de um processo anafórico, isto é, olhando para um "antes", um passado. O efeito de sentido produzido pelo enunciado na enunciação é determinado por um já-dito em um movimento único, unilateral: é a memória discursiva que determina o sentido do enunciado. 


\section{A noção de acontecimento enunciativo e seu efeito catafórico (SHE)}

Já para a SHE, o acontecimento é sempre o início de um outro, produzindo um efeito catafórico, posterior, uma vez que, devido à influência dos estudos ducrotianos para a constituição dessa disciplina - Semântica Argumentativa -, a noção de argumentação conduz o texto incessantemente para o futuro, o impede de "terminar". Não que não haja um passado, como se verá, mas que a atenção analítica acaba por recair sobre as orientaçôes futuras interpretativas. Autores como Ducrot (1987), Carel e Ducrot (2001), Guimarães (2002, 2007, 2009), Schreiber da Silva (2004) nos permitem dizer que, para apreendermos de modo sucinto os efeitos do acontecimento da SHE, usaremos o termo catáfora para condensar noções que constituem o a priori da SHE, por serem determinadas por um futuro: perspectiva, conclusão, orientação, interpretação, futuridade, latência, textualidade, argumentatividade.

Por outro lado, mesmo quando sabemos que a SHE também trata de "passado", esse é distinto do passado da AD. Para ponderarmos a relação entre acontecimento discursivo e acontecimento enunciativo, precisamos perscrutar as especificidades do "passado" nos dois campos de saber, em que são distintas. Há uma diferença básica: se o acontecimento discursivo na $\mathrm{AD}$ é determinado por um passadojá-lá (PÊCHEUX, 2009), independente do presente, que se atualiza ao tornar-se presente, o acontecimento enunciativo na SHE é determinado por um passado aqui, chamado de memorável (GUIMARÃES, 2002), um passado que não recorre a um lugar anterior, mas, embora passado, se encontra e faz parte do presente do dizer: "o memorável não é um conceito discursivo. Não se trata de um antes discursivo" (SCHREIBER DA SILVA, 2011, p.3). Para a SHE, o presente do dizer não recorre a outro lugar, um já-dito, mas recorta, no próprio enunciado, um memorável. Portanto, se o passado da AD é apreendido por um interdiscurso, o passado da SHE é apreendido por um recorte de memorável no próprio enunciado (por um gesto de "encontrar no presente do dizer um enunciado anterior"). Entre tantos movimentos de passado, podemos dizer que há uma diferença sutil: para a $\mathrm{AD}$ o interdiscurso é a noção que propicia uma atualização (trazer um passado para o presente, produzindo o sentido); para a SHE, o memorável é a noção que propicia um recorte (encontrar um passado no interior de um presente, conduzindo o dizer a uma orientatividade futura, cerne argumentativo). Logo, a noção de passado, cara para a constituição do sentido, 
tanto para a SHE quanto para a $\mathrm{AD}$, é procedimentalmente distinta em ambas as teorias: temos um passado lá (AD) e um passado aqui (SHE), como percebeu Schreiber da Silva (2011, p. 3): [na SHE] "interessa a memória que foi recortada e não a rede de enunciações de um antes”.

É bom que se diga que o aspecto argumentativo sempre determinou fortemente a SHE devido ao apreço que muitos pesquisadores e instituições praticantes dessa vertente tiveram e têm pelo estruturalista francês Oswald Ducrot. Por isso, a última perspectiva teórica desse autor (CAREL; DUCROT, 2001) sobre Blocos Semânticos afetou diretamente, mais uma vez, as abordagens teóricas da SHE. Por exemplo, onde antes Guimarães utilizava a prática do interdiscurso (1995), passa a utilizá-la ladeada com a noção de memorável (Id. 2002) e finalmente passa a abandoná-la totalmente em seus trabalhos (Id. 2009) e utilizar unicamente a noção de memorável para operar as análises. Desse modo, a teoria da SHE alcança mais um refinamento singular, fronteirizandose com a vizinha $\mathrm{AD}$ : a explicitação do passado para a SHE não depende de uma busca da memória discursiva para atualizá-la, como na $\mathrm{AD}$, mas simplesmente de um gesto interpretativo, que opera o passado no presente, como explica Guimarães:

[...] o acontecimento de linguagem não se dá no tempo, nem no tempo do locutor, mas é antes, um acontecimento que temporaliza: uma temporalidade em que o passado não é um antes, mas um memorável, recortado pelo próprio acontecimento que tem também um futuro como uma latência de futuro. O sujeito não fala no presente, no tempo, embora o locutor o represente assim, pois só é sujeito enquanto afetado pelo interdiscurso, memória de sentidos, estruturado pelo esquecimento, que faz a língua funcionar. Falar é estar nessa memória, portanto, não é estar no tempo (dimensão empírica). O acontecimento em que se fala é, do meu ponto de vista, espaço de temporalização (2002, p. 14).

Portanto, não se trata de uma teoria não falar em futuro e outra não falar em passado, muito pelo contrário. O que há é uma predominância metodológica na distinção da noção de acontecimento: enquanto muitos trabalhos em $\mathrm{AD}$ esmiúçam formas de apreender o passado na constituição de um sentido (passado, história, memória, pré-construído, interdiscurso, já-lá, anterioridade, antes etc), 
muitas pesquisas em SHE, comumente, sem abrir mão de um passado (que difere do passado da $\mathrm{AD}$, como dito, e é chamado de memorável), primam por tratar o sentido já como um futuro (orientatividade e textualidade).

Ao traçarmos essas pontuaçóes, uma ressalva é necessária. Nossas asseverações engendram duas bases: primeiro, nosso objeto de estudo é a distintividade e a relação entre $\mathrm{AD}$ e $\mathrm{SHE}$, e segundo, para efetivar este estudo, perfazemos um corpora amplo, um acervo de inúmeras pesquisas em ambas as áreas, que são irreproduzíveis aqui por razões espaciais, o que limita nossa indicação obra-aobra, mas não compromete, cremos, nossa verificabilidade.

Ao observarmos as definiçóes de acontecimento para a $\mathrm{AD}$ e para a SHE, podemos dizer que, apesar de certa aproximação, ambas tratam esse dispositivo de forma peculiar. E, cada qual a seu modo, dispóem de aspecto tritemporal linguístico (presente, passado e futuro) - $\mathrm{AD}$ : memória, enunciado e interpretação, ou outras reescrituras diversas, como constituição e formulação em Orlandi (2006); memória, atualização e antecipação em Courtine (2009), condensados e totalizados na palavra discurso; e para a SHE: memorável, formulação e orientação, como em Guimarães (2002), ou outras reescrituras diversas, condensados e totalizados na expressão enunciação.

Isso nos ajuda a sustentar que talvez uma das principais distinçôes marcantes entre AD e SHE seja de fato o que estamos chamando aqui de predominância metodológica. Isto é, embora as duas vislumbrem a investigação do sentido, o que há entre SHE e AD são predominâncias metodológicas para trabalhar esse sentido, que engendram dois objetos distintos (acontecimento discursivo e acontecimento enunciativo), que as separam como teoria.

\section{Pequena análise do acontecimento discursivo e do acontecimento enunciativo}

De forma bem sucinta, sem buscar aprofundamento, mas apenas justificar e ratificar as considerações acima, analisemos o enunciado:

(5) Enem de novo: sim ou não

Pelo acontecimento discursivo, agenciados por uma metodologia anafórica, podemos, dentre tantos dispositivos disponíveis de autores $\mathrm{da} \mathrm{AD}$, "ir a um lugar passado" e operar a expressão "de novo" pelo dispositivo do interdiscurso, por 
exemplo (enunciados, no plural, que explicitam dificuldades em se executar o processo avaliativo do Enem), da memória (o problema específico da troca de enumeração das questôes da prova de 2010 e a gravidade de não coincidência com o gabarito), da formação discursiva (onde se observam duas ideologias: uma governamental, que apoia a eficácia e ajuste do Enem, produzindo um efeito de legalidade da prova, e outra populacional, que refuta e exige compensação, produzindo um efeito de ilegalidade da prova) etc. É claro que, independentemente de resultados de análise, a $\mathrm{AD}$ prima por uma metodologia anafórica (a investigação de um antes, o a priori histórico (MILANEZ; GASPAR, 2010)).

Já pelos dispositivos comumente usados para tratar o acontecimento enunciativo, agenciados por uma metodologia catafórica, podemos "ir a um futuro textual" (a enunciação de um passado problemático que reclama uma intervenção futura), que pode ser mobilizado por pelo menos quatro noções: 1) pela Argumentação, como orientação futura, cf. Guimarães (2007): o memorável (problema da confusão enumerativa da prova) em si já é argumento que remete a uma futuridade: uma outra prova seria necessária ou não? $\mathrm{O}$ memorável é argumento para uma conclusão (por fazer): uma intervenção (ou não), outra prova; 2) pela Textualidade, como continuação constante do dizer que perfaz unidades de sentido, cf. Guimarães (2011): o objeto Enem apresenta seu desenrolar há muito tempo. Cada acontecimento do Enem perfaz novos textos. No caso do enunciado acima, mediante as problemáticas, a textualidade sugere enunciados futuros do semanticista (por fazer) sobre a possibilidade do sim ou do não, como mostra o aposto "sim ou não"; 3) pelo Político, como divisão e redivisão do dizer, cf. Guimarães (2002): na mesma situação acima, como não há consenso entre realizar ou não uma outra prova ("sim ou não"), a futuridade eterniza-se nesse embate, e uma análise pelo viés político deverá debruçar-se sobre uma posteridade litigiosa, em que o semanticista deverá descrever e identificar sentidos decorrentes desse embate insolúvel; 4) pela Designação, como sentido proveniente de um texto onde a palavra ocorre (e não em um passado), cf. Guimarães (2002; 2011): aqui, o significado (determinação) de Enem, baseado no enunciado acima, recortará o memorável de definição como "avaliação necessária para o Governo" ou a "importância para ingresso no ensino superior", bem como "organização obsoleta", "falhas" etc. E tudo isso orientará a análise para a futuridade de determinações como "optimização do Enem", "aperfeiçoamento", "inapropriado" etc. A análise pela designação sempre deixa uma abertura para 
interpretaçōes futuras sobre o objeto designado. Ainda mais em casos polêmicos, como o objeto Enem.

Conclusivamente, pelo modo que traçamos essa sucinta análise de cunho apenas ilustrativo (que, claro, poderia ter direçôes distintas), podemos ponderar que as metodologias da $\mathrm{SHE}$ e $\mathrm{AD}$ podem (não que devam) desvelar uma predominância analítica na seguinte direção (e ao levar em conta o grande acervo de pesquisas na direção similar à que traçamos, cremos ter uma boa constatação disso):

(5a) Discursivamente, "de novo" parafraseia-se em "um anterior não foi satisfatório". Leva-se em conta o a priori histórico, a memória, o interdiscurso, o já-dito, o já-lá).

(5b) Enunciativamente, "de novo" parafraseia-se em "um posterior será mais satisfatório". Leva-se em conta a argumentação, a textualidade, o político e a designação).

É muito óbvio que, como já dito, um e outro, a seus modos, abordam presente, passado e futuro, mas, mesmo que a $\mathrm{AD}$ também fale da posterioridade (se a prova anterior não foi plausível, uma futuridade se desponta), e a SHE fale da anterioridade (futuridade é inevitável porque a anterioridade da prova não atingiu expectativas), suas noçóes teóricas, a partir do modo como operamos acima, parecem acentuar essas direçōes metodológicas no vasto rol de pesquisas brasileiras.

Podemos sustentar o que dizemos em (5a) baseado no pressuposto de que, quando se fala em discurso, pensamos o funcionamento linguístico sempre em relação com a história, um antes, um a priori histórico (MILANEZ; GASPAR, 2010). Por isso dizemos que analisar pelo lugar epistemológico da AD é assumir um procedimento anafórico (que mobiliza um antes) no qual o discurso é uma "reconfiguração incessante" mobilizada pela história (COURTINE apud MILANEZ; GASPAR, 2010, p. 9).

E podemos defender o que afirmamos em (5b) baseados no pressuposto de que, quando falamos em acontecimento, pensamos o funcionamento enunciativo independente de "um passado lá" em detrimento de um "passado aqui" (o memorável). Isto é, pensamos o funcionamento linguístico com olhar na futuridade, um depois. A razão da mobilização de um memorável é a futuridade, a conclusão (GUIMARÃES, 2007). Por isso dizemos que analisar pelo lugar epistemológico da SHE é assumir um procedimento catafórico (que prioriza um depois), no qual o dizer é conduzido incessantemente para um futuro (idem). 


\section{A noção de sujeito: uma exigência da atualidade Linguística}

Outro conceito presente na SHE e na $\mathrm{AD}$ que merece nossa atenção é o de sujeito. Se atualmente o sujeito é quase que conceito obrigatório em certas linguísticas, era desconsiderado como pertinência científico-linguística e não era sequer aceito em pesquisas "sérias", como elemento razoável e propício de análise, até meados dos anos 60, devido à forte corrente do Estruturalismo, em voga desde a Publicação do Curso de Linguistica Geral, em 1919, razão pela qual Benveniste, por exemplo, preferiu expor seus estudos da linguagem no âmbito da filosofia, uma vez impedido de falar em subjetivismo na dimensão Linguística. $\mathrm{O}$ quadro mudou drasticamente na atualidade, pois a ordem do dia agencia o pesquisador a, inevitavelmente, de algum modo, ter de perscrutar a noção de sujeito ou, de outro modo, ter de aceitar uma corrente em que "fazer Linguística é ter de tocar na assuntologia do sujeito" (enumerados infinitamente: leitor, escritor, locutor, enunciador, autor, emissor, receptor, pensador, personagem, falante, outro etc, bem como suas especificidades sociais infindas, como: lexicógrafo, etimologista, filologista, gramaticista, semanticista, analista, tradutor etc).

Sem alongar as descrições das tendências de estudos contemporâneos e suas determinantes, fato é que, com a ascensão de certas pesquisas que privilegiavam o sujeito como elemento da língua, como as de Benveniste e demais pesquisadores, o sujeito, atualmente, mostra-se como noção indiretamente "obrigatória" para trabalhos de Linguística em geral. Assim, convém, para cumprir nosso trabalho de fronteirizar SHE e $\mathrm{AD}$, entendermos também as distinçôes entre o sujeito da SHE e da AD, retendo suas particularidades. Vejamos as distintividades de sujeitos no arcabouço teórico da $\mathrm{AD}$ e SHE.

\section{O sujeito na $A D$}

Para a Análise do Discurso o sujeito é interpelado ideologicamente e sua prática discursiva reflete esse imaginário que o afeta. $\mathrm{O}$ sujeito se coloca na história quando usa a língua e daí decorrem os sentidos. É assim que a língua se relaciona com a exterioridade (história), por isso é que não existe discurso sem sujeito. E não existe sujeito sem ideologia (PÊCHEUX, 2009). A ideologia e o sujeito estão ligados pela língua. Para que a língua faça sentido é preciso que a história intervenha. O sujeito sofre determinações históricas que especificam o 
que pode e deve ser dito, em uma conjuntura dada, sendo materialmente dividido desde sua constituição: ele é "sujeito de" e é "sujeito à". Ele é sujeito à língua e à história, pois para se constituir, para produzir sentidos, é afetado por elas. Ele é afetado, pois se não se submeter à língua e à história ele não se constitui, ele não fala e não produz sentidos.

O sujeito é pensado como posição, o indivíduo precisa ocupar uma posição para ser sujeito do que diz. Ao enunciar assume diferentes posiçôes discursivas. É nesse sentido que se revela cindido e fragmentado, podendo alterar sua posição discursiva de momento em momento ou de contexto para contexto, caracterizando-se como ambíguo e instável.

Orlandi (2009) destaca que os sujeitos enunciam sempre mais do que desejam enunciar; nunca sabem completamente o que enunciam, pois há, na linearização discursiva, um algo a mais, originário da determinação histórica e ideológica. O sujeito se torna efeito de sentido do discurso, envolvido pelos esquecimentos mencionados por Pêcheux (1997).

No esquecimento 1, tem-se um caráter ideológico, que faz com que o sujeito apague qualquer elemento que remeta ao exterior de sua formação discursiva, para o que "aceita" e "recusa" determinados enunciados, com o propósito de produzir certos efeitos de sentido. O esquecimento 2 leva o sujeito a definir fronteiras entre o que pode e deve ser dito e o que não pode ser dito. Esse procedimento culmina na ilusão da objetividade discursiva ao representar a realidade, conferindo ao sujeito a origem e a fonte do sentido. A ilusão discursiva da unidade e da origem tornase necessária para a manutenção da identidade, a qual tem seu fechamento perpassado pela alteridade que irrompe no interior de um sujeito marcado pela dispersão das várias posições que assume no discurso.

\section{O Sujeito na SHE}

Para a SHE o sujeito é constituído na e pela temporalidade do acontecimento:

os falantes não são os indivíduos, as pessoas que falam esta ou aquela língua. Os falantes são estas pessoas enquanto determinadas pelas línguas que falam. Neste sentido, falantes não são as pessoas na atividade físico-fisiológica, ou psíquica, de falar. São sujeitos da língua enquanto constituídos por este espaço de línguas e falantes que chamo espaço de enunciação (GUIMARÃES, 2002, p. 18). 
O falante constitui-se como categoria linguística e enunciativa, formado pelos espaços de enunciação. A enunciação é uma prática política; ao falar assumese a palavra no espaço enunciativo, o qual se encontra dividido pelas línguas e pelos falantes. No acontecimento os lugares enunciativos - ou seja, as configuraçôes específicas do agenciamento enunciativo para "aquele que fala" e "aquele para quem se fala" - não são pessoas, mas lugares formados a partir dos dizeres e configuram-se pelo agenciamento enunciativo. Falar implica certa obediência e / ou certo embate: portanto, podem-se dizer determinadas coisas, mas outras não; permite-se falar de alguns lugares de locutor e não de outros, a ter certos interlocutores e não outros. O falante, ao assumir a palavra, está marcado pelas línguas que o constituem como ser simbólico e se sujeita ao agenciamento político - próprio do espaço de enunciação.

\section{Aproximações e distanciamentos entre os sujeitos da SHE e da $A D$}

Ao compararmos a $\mathrm{AD}$ e a $\mathrm{SHE}$ notamos certa proximidade quanto à acepção de sujeito, observadas suas devidas peculiaridades: ambas entendem que no espaço enunciativo o falante sofre restrições quanto ao que pode e ao que não pode dizer; e, ainda, quanto às posiçōes que assume ao enunciar, pois pode falar a partir de alguns lugares específicos e não de outros. Apesar dessa contiguidade, as determinaçôes de sujeito, em cada perspectiva teórica, diferem nos seguintes aspectos: na $\mathrm{AD}$ o sujeito é constituído por meio da história e da ideologia. $\mathrm{E}$ na SHE o sujeito é formado na e pela temporalidade do acontecimento e, também, pelo espaço da enunciação. O sujeito, ao enunciar, insere-se em uma cena particular, a qual é analiticamente entendida de forma diferenciada na SHE e na $\mathrm{AD}$.

Para a SHE, a cena enunciativa abrange modos característicos de acesso à palavra por meio de relações estabelecidas entre as figuras da enunciação e as formas linguísticas. Guimarães define esse termo como "especificaçōes locais no espaço de enunciação" (2002, p. 23). Trata-se de um espaço particularizado por uma deontologia específica de distribuição e divisão dos lugares enunciativos no acontecimento: refere-se a "aquele que fala" e "aquele para quem se fala". A cena enunciativa mobiliza o modo de construção dos lugares de dizer.

Ainda é digno de nota o fato de que, quando se trata da SHE, o uso do termo "sujeito" é menos recorrente, uma vez que suas particularidades são 
operadas a partir da tripla noção "Locutor, locutor e enunciador" (L, l-x, E). O sujeito para a SHE é um falante que, ao falar, torna-se esses L, l-x, e E. Ou melhor, não se fala em sujeito na SHE, fala-se em "disparidade do sujeito" (um único personagem disparizado em três faces: $\mathrm{L}, \mathrm{le} \mathrm{E}$ ). Ao compararmos o sujeito na $\mathrm{AD}$ e na SHE chegamos ao DSD abaixo:

$\mathrm{AD}$

História $-\mid \quad$ Sujeito $\quad \mid-$ Ideologia

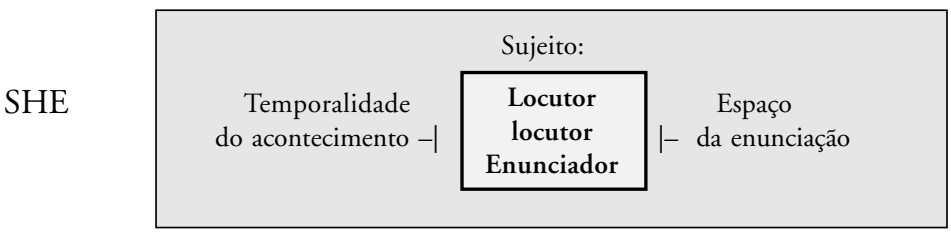

Figura 5

\section{A cena enunciativa na SHE}

A cena enunciativa, pelo prisma da SHE, é instaurada por um acontecimento enunciativo. Ela é assim chamada porque é palco de três disposições de sujeito (Locutor, locutor e enunciador) ou, como prefere Schereiber da Silva (2009), na cena vislumbra-se uma disparidade de sujeito: o Locutor (com maiúscula ou L) refere-se ao lugar que se representa no próprio dizer, como sua fonte, especificando o tempo do dizer como contemporâneo de si, ou seja, de L. Ao se conceber como origem do dizer, L também se obriga a uma divisão, pois, para encontrar-se nesse lugar, é preciso estar afetado por lugares sociais que o autorizem a falar como falante. Portanto, para que o Locutor apresente-se como origem do que enuncia é necessário que ele seja um lugar social de locutor, o qual é denominado locutor$\mathrm{x}$ (com minúscula ou l). Esse locutor sempre estará predicado por um lugar social que a variável $\mathrm{x}$ indica. Para exemplificar podemos pensar no professor, o qual, ao ministrar sua aula, apresenta-se como locutor-x, ou seja, locutor-professor. Ele é considerado um lugar social que autoriza enunciar como L. Ao dar sua aula ele pode colocar-se como origem dela. Dessa forma, para o Locutor, só é possível assumir a palavra para lecionar e apresentar-se como origem do que leciona ao posicionar-se como locutor-professor falante de uma língua própria do espaço em que está inserido. 
Há, então, uma distinção entre o Locutor e o lugar social do locutor, responsável por caracterizar L como desigual a si próprio: é apenas quando o Locutor se mostra como locutor-x (lugar social) que ele se torna Locutor.

A cena enunciativa ainda gera outra divisão do locutor: a do enunciador ou simplesmente $\mathrm{E}$, responsável por produzir os lugares de dizer. O enunciador, além de individual (um lugar de dizer com foco na individualidade), pode ser também universal (é um lugar que submete o Locutor ao verdadeiro e ao falso ao dizer sobre os fatos do mundo; pode-se pensar aqui no discurso científico); e genérico (o que se diz é dito como aquilo que todos dizem. Para ilustrar temos os ditos populares). Assinalamos aqui os modos de $\mathrm{L}$ desconhecer que sempre fala de um lugar social e histórico.

Assim, a perspectiva teórica da SHE apresenta a cena enunciativa dividindo o locutor em distintas figuras: $\mathrm{L}$ - o locutor que se representa como a origem do dizer; l-x - o lugar social do locutor que mobiliza os papéis enunciativos na cena; $\mathrm{e} \mathrm{E}$ - o lugar de dizer. Essa divisão é necessária para que o locutor funcione por meio da língua.

\section{A cena enunciativa na $A D$}

Após nos determos nas especificações da cena enunciativa na SHE, direcionamos nosso olhar para a configuração desse dispositivo analítico na $\mathrm{AD}$, tendo como orientação teórica Maingueneau (2004). Esse estudioso distingue três cenas constituintes da cena da enunciação: cena englobante, cena genérica e cenografia. A cena englobante diz respeito ao estatuto pragmático do tipo de discurso a que pertence um texto. Nessa perspectiva, se faz necessário pensarmos em como o discurso interpela o leitor. Para ilustrar podemos pensar na seguinte situação: jornais editados mensalmente por um sindicato representativo dos trabalhadores. Ao receber esse periódico, o sujeito deve ser capaz de identificar a qual tipo de discurso ele pertence (religioso, midiático, publicitário, político, sindical...). O coenunciador é interpelado a partir de um lugar social bem definido: o de trabalhador e cidadão integrado a um grupo social específico.

$\mathrm{Na}$ sequência, temos a cena genérica, a qual é definida por gêneros específicos e apresenta papéis para seus parceiros, circunstâncias, um suporte material, um modo de circulação, uma finalidade etc. Retomando o exemplo usado acima, de maneira simplificada, podemos pensar que o jornal produzido pelo sindicato pertence ao gênero reportagem jornalística, tendo como sujeito 
enunciador uma instituição sindical, figurativizada por sujeitos empíricos - os sindicalistas, cuja fala é incorporada aos textos por meio do discurso direto. $\mathrm{O}$ enunciatário nesse fazer discursivo é o trabalhador.

A última cena que integra a cena da enunciação é a cenografia, a qual não é imposta pelo gênero discursivo, mas construída pelo próprio discurso. Ela é, simultaneamente, aquilo de onde vem o discurso e aquilo que esse discurso engendra e assim legitima um enunciado que deve legitimá-la. A cenografia é “[...] uma enunciação (que) se caracteriza, de fato, por sua maneira específica de inscrever-se, de legitimar-se, prescrevendo-se um modo de existência no interdiscurso (MAINGUENEAU, 2005, p.76). Revisitando a exemplificação dos jornais produzidos pelo sindicato trabalhista, podemos dizer que durante sua leitura espera-se encontrar, previsivelmente nesse periódico, reportagens jornalísticas. Entretanto, não é impossível nos depararmos com uma cenografia diferenciada em meio à reportagem: o enunciador pode não se ater à cenografia rotineira desse gênero e interpelar o leitor como se mantivesse com ele uma "conversa informal". Essa conversa comporia a cenografia construída pelo texto, a qual poderia manifestar-se através de outras cenografias (carta, e-mail, propaganda...) sem alterar a cena genérica. Além de um enunciador e um enunciatário, a cenografia implica uma cronografia (um momento) e uma topografia (um lugar), a partir das quais o discurso pretende surgir. Ao olharmos cada cena que integra a cena da enunciação, destacamos que se dão de forma simultânea e inter-relacionadas. E, ainda, concluímos que a fala envolve uma cena enunciativa que é validada progressivamente por meio da própria enunciação.

Diante dessas informações referentes à cena enunciativa, tanto no âmbito da AD quanto no da SHE, é possível elaborar o seguinte DSD para sintetizar as peculiaridades de cada abordagem:

SHE

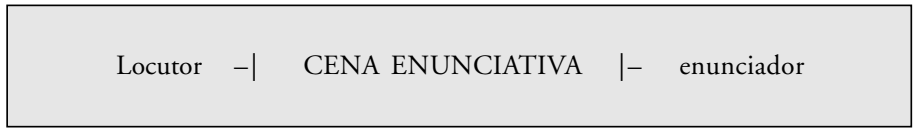

$\mathrm{AD}$

Cena englobante

$\perp$

Cena genérica $-\mid$ CENA ENUNCIATIVA $\mid-$ cenografia

Figura 6 
Para exemplificarmos, sucintamente, como se dá a compreensão da cena enunciativa na AD e na SHE, tomemos o enunciado: "Vamos lutar por nossos direitos e garantir a reposição salarial", publicado em um jornal editado por um sindicato dos trabalhadores. Então poderíamos traçar o seguinte quadro em cada perspectiva teórica ao olharmos o mesmo acontecimento:

\begin{tabular}{|c|c|c|c|}
\hline \multicolumn{2}{|r|}{ SHE } & \multicolumn{2}{|r|}{$\mathrm{AD}$} \\
\hline Locutor & $\begin{array}{l}\text { Origem do dizer: especificado } \\
\text { pelo verbo "Vamos". A primeira } \\
\text { pessoa do plural representa o seu } \\
\text { presente como o tempo do dizer. }\end{array}$ & $\begin{array}{l}\text { Cena } \\
\text { englobante }\end{array}$ & Discurso sindical \\
\hline locutor-x & $\begin{array}{l}\text { Locutor-sindicalista: representa o } \\
\text { lugar social que autoriza } \mathrm{L} \text { a falar. }\end{array}$ & $\begin{array}{l}\text { Cena } \\
\text { genérica }\end{array}$ & $\begin{array}{l}\text { - Gênero reportagem } \\
\text { jornalística; } \\
\text { - Enunciador: instituição } \\
\text { sindical } \\
\text { - Enunciatário: trabalhadores }\end{array}$ \\
\hline Enunciador & $\begin{array}{l}\text { Lugar de dizer: temos um } \\
\text { enunciador coletivo, que assume } \\
\text { a palavra representando uma } \\
\text { coletividade (a classe dos } \\
\text { trabalhadores) }\end{array}$ & Cenografia & $\begin{array}{l}\text { - Cronografia: marca o tempo } \\
\text { da enunciação. No exemplo } \\
\text { citado, pode-se observar a data } \\
\text { de publicação do jornal no } \\
\text { qual está o enunciado. } \\
\text { - Topografia: refere-se ao lugar } \\
\text { enunciativo, ou seja, à figura } \\
\text { do sindicalista. } \\
\text { - Sujeitos do discurso: } \\
\text { sindicalista e trabalhadores }\end{array}$ \\
\hline
\end{tabular}

Figura 7

Cada linha teórica aborda seu objeto de forma específica ao descrever a cena da enunciação. Conforme vimos, a SHE tem na sua cena o sujeito como categoria de dizer, que, ao enunciar, divide-se em três ( $\mathrm{L}, \mathrm{l}-\mathrm{x}$ e E), como que a $\mathrm{AD}$ possui a própria cena desmembrada em outras três (cena englobante, cena genérica e cenografia). Embora corra menos risco de confusão sinonímica do que os dispositivos analíticos de acontecimento, memória, sujeito e temporalidade, acima discutidos, é bom que se diga que o emprego homônimo de cena enunciativa na SHE e $\mathrm{AD}$ não são passíveis de relações sinonímicas, e que a disposição ladeada entre cada um dos itens do quadro não significa relação direta entre os termos teóricos, mas apenas um panorama visual reflexivo. 


\section{Considerações Finais}

Metodologicamente dizendo, foi inevitável que se resenhasse, em alguns momentos, o arcabouço teórico da SHE e da $\mathrm{AD}$, uma vez que nosso objeto de estudo era a própria teoria. Ao findar um artigo metateórico, alguns esclarecimentos se perfazem. Eis o logro da teoria: a possibilidade de articular um dado por vias abstratas. Logo, onde esse instrumento falha, perspectivas de uma nova teoria se desponta. E não é difícil dizer que a teoria sempre oscila. Refaz-se. Renovase como uma Fênix. Também foi visto que, devido às condiçôes das práticas linguísticas atuais (que exigem facilitação didática e ecleticidade de ementa acadêmica), a comparação teórica inevitavelmente acontece. Contudo, embora seja inevitável, pode ser agenciada por questōes que mereçam relevo. Diante desse quadro, é importante tecer três comentários finais:

Primeiro: é importante salientar que, com essas asseverações descritivas e situacionais dos campos teóricos da $\mathrm{AD}$ e $\mathrm{SHE}$, não queremos causar um efeito de "fechamento" para ambas as teorias. Até porque do ponto de vista da AD, ela não se ancora em nenhuma dimensão de saber, senão no entremeio dessas dimensōes (ORLANDI, 1996), o que pode conclamar outras determinaçōes e associações. Do mesmo modo, conforme a SHE, o sentido não estaciona no interior da língua, mas deve explorar o "fora" da língua, esteja ele onde estiver, na dimensão social, histórica, filosófica, psicanalítica, podendo também explicitar outras determinações e filiaçôes. Essas duas máximas de mobilidade propiciam um eterno oscilar teórico para SHE e $\mathrm{AD}$, movido pela criticidade que se impõe a cada nova pesquisa, o que não significa que o pesquisador deva operar sem satisfatoriedade de rigor limítrofe de teoria, sem definir muito bem suas constantes, variantes, objetos, unidades e sujeitos, como propôs Benveniste (2006) que deveria ser qualquer saber da Linguística.

Embora nos empenhemos em traçar algumas distintividades, um fechamento em determinado ângulo desprestigia o raciocínio movediço dessas teorias. Outras determinações e diferentes relações não só podem ser possíveis como podem ser produtivas. Contudo, neste trabalho, levados pela urgente necessidade de especificar uma configuração de limite entre teorias vizinhas, que a prática linguística atual exige, e também agenciados pelos não raros equívocos de sinonímia, miscelânea e inconsistência científica no interior dessa prática linguística no cenário acadêmico atual, que reclamam um parecer satisfatório de constituição / distinção teórica entre SHE e $\mathrm{AD}$, nos moldes aqui discorridos, 
procedemos trazendo questões informais de incógnitas teóricas para serem sanadas (ou discutidas) no âmbito formal da Linguística, através de recortes aqui levantados.

Segundo: a diferenciação entre $\mathrm{AD}$ e SHE não significa que se queira estabelecer proibições e limites entre as noções que se usam aqui e ali, e que se usam por empréstimos. O que se deve é ter o cuidado analítico e o primor científico de, ao usar uma noção da AD na SHE ou da SHE na AD, por empréstimo, que se tenha dois pontos de atenção: o empréstimo deve ser pertinente, baseado na noção cautelar de "inconsistência científica", isto é, se se toma algo de outro lugar, é porque no lugar residente não há tal abordagem que careça dessa noção ainda e necessita-se dela. E, caso seja de fato necessário tomar certo aparato por empréstimo, deve haver um preparo de reescrita dessa noção, para que o aparato possa ser utilizado pelo modo de raciocínio do lugar teórico emigrante. Se apenas toma-se por empréstimo sem reescrita adequada, significa igualmente miscelânea. Falta de cuidado que pode comprometer involuntariamente a análise, uma vez que uma simples noção não se resume nela mesma, mas uma noção é uma condensação de toda uma vasta prática analítica.

Terceiro: se por um lado é apreciável dominar o mecanismo teórico de várias teorias como um "enciclopedismo teórico", exigência didática, editorial e de mercado, que nada mais é que a história das ideias linguísticas filtrada por essas necessidades atuais sociais, por outro lado, o que fazer com todo esse enciclopedismo epistemológico em pesquisas já é tarefa sofisticada. O pesquisador precisa desenvolver um requinte para situar-se em uma faixa de gaza linguistica que algumas necessidades exigem. Embora opere por uma conveniência micro, devese aprimorar um olhar macro na Linguística que otimize a história das ideias linguísticas e robusteça seu prisma teórico de visão, sem contudo embaraçar seu olhar entre a exigência social (de enquadramentos convenientes) e a necessidade científica (de satisfatoriedade analítica).

\section{Notas}

${ }^{1}$ Arqui-politica: traz o efeito de "submissão / organização"; para-politica: gera o efeito de "neutralização / pacificação de conflitos"; e meta-política: dá o efeito de "embate / litígio" (cf. RANCIÈRE, 1996).

${ }^{2}$ Para um melhor aprofundamento desse tópico, ver Machado (2010). 
${ }^{3} \mathrm{Na}$ Semântica Histórica da Enunciação, os fatores sócio-históricos sustentam o funcionamento que, por sua vez, orienta para a produção de um efeito de sentido. ${ }^{4} \mathrm{Na}$ Análise de Discurso, a fala, sustentada pela discursividade, orienta para a ideologia que, por sua vez, orienta para a produção de um efeito de sentido.

${ }^{5}$ DSD: Domínio Semântico de Determinação. Trata-se de sinais utilizados para visualizar a análise (GUIMARÃES, 2009): os sinais 'e+ significam "determina”, e a barra significa "antonímia".

${ }^{6}$ PRADO, M. Enem de novo: sim ou não. IG: Último segundo, 10 de Nov. 2010. Disponível em <http://ultimosegundo.ig.com.br/colunistas/mateusprado $>$. Acesso em 29 de out de 2011.

\section{Referências}

ALTHUSSER, L. Aparelhos Ideológicos de Estado. 6. ed. Trad. Walter José Evangelista e Maria Laura V. de Castro. Rio de Janeiro: Edições Graal, 1998.

AUSTIN, J.L. How to do things with words. Oxford: Clarendon, 1962.

AUROX, S. Língua e hiperlíngua. In: Línguas e instrumentos lingüisticos, Campinas: Pontes, n. 1, p. 17-30, jan/jun. 1998.

BAKHTIN, M. Marxismo e filosofia da linguagem. São Paulo: Hucitec, 2004.

BALLY, C.; SECHEHAYE. A. Curso de Lingüistica Geral. Trad. Antônio Chelini et al. São Paulo: Cultrix, [1916] 1995.

BENVENISTE, E. Problemas de Linguística Geral II. Campinas: Pontes, 2006.

CAREL, M., DUCROT. O. O problema do paradoxo em uma semântica argumentativa. Tradução de Sheila Elias de Oliveira. In: GUIMARÃES, E. Línguas e instrumentos lingüísticos, n. 8. Campinas: Pontes, 7, 2001.

COURTINE, J. J. Análise do discurso político: o discurso comunista endereçado aos cristãos. São Carlos: Editora Edufscar, 2009.

CHOMSKY, N. Linguagem e mente. Trad. Lúcia Lobato et al. Brasília: UNB, 1998. DUCROT, O. O dizer e o dito. Trad. Eduardo R. J. Guimarães. Campinas: Pontes, 1987.

GADET, F.; PÊCHEUX, M. A lingua inatingível: o discurso na história da lingüística. Trad. Bethania Mariani e Maria Elizabeth C. de Mello. Campinas: Pontes, 2004. 
GUILHAUMOU, J.; MALDIDIER, D. Da enunciação ao acontecimento discursivo em análise de discurso. In: GUIMARÃES, E. (Org.). História e sentido na linguagem. Campinas: Pontes, 1997.

GUIMARÃES, E. Os limites do sentido. Campinas: Pontes, 1995.

GUIMARÃES, E. Semântica do acontecimento. Campinas: Pontes, 2002.

GUIMARÃES, E. Texto e argumentação: um estudo de conjunçōes do português. Campinas: Pontes, 2007.

GUIMARÃES, E. A enumeração: funcionamento enunciativo e sentido. Cadernos de Estudos Linguisticos, v.1, n. 51. Campinas: Editora da UNICAMP, 49-68, 2009 GUIMARÃES, E. Análise de texto: procedimentos, análises, ensino. Campinas: Editora RG, 2011.

JAKOBSON, R. Linguistica e comunicação. São Paulo: Cultrix, 2005.

MACHADO, J. C. Um estudo designativo em fronteiras enunciativas: a corrupção pelo prisma da Semântica Histórica da Enunciação. 219f. 2010. Dissertação (Mestrado) - Universidade Federal de São Carlos, 2010.

MAINGUENEAU, D. Ethos, cenografia, incorporação. In: AMOSSY, R. (Org.) Imagens de si no discurso: a construção do ethos. São Paulo: Contexto, 2005. p. 69-92. MAINGUENEAU, D.; CHARAUDEAU, P. Dicionário de análise do discurso. São Paulo: Contexto, 2004.

MARCUSCHI, L. A. Produção textual, análise de gêneros e compreensão. São Paulo: Parábola, 2008.

MILANEZ, N.; GASPAR, N. R. A (des)ordem do discurso. São Paulo: Contexto, 2010.

ORLANDI, E. Interpretação: autoria, leitura e efeitos do trabalho simbólico. Campinas: Pontes, 1996.

ORLANDI, E. A linguagem e seu funcionamento. Campinas: Pontes, 2006.

ORLANDI, E. As formas do silêncio. Campinas: Ed. da UNICAMP, 2007.

ORLANDI, E. Aula sobre aspectos teóricos gerais, ministrada em 12 de março de 2008 no IEL/UNICAMP, na Disciplina Discurso e Subjetividade, 2008.

ORLANDI, E. Análise do discurso: princípios e procedimentos. Campinas: Pontes, 2009. PÊCHEUX, M. Discurso: estrutura ou acontecimento. Campinas: Pontes, 1990. PÊCHEUX, MICHEL. Semântica e discurso: uma crítica à afirmação do óbvio. Trad. de Eni P. Orlandi. 3. ed. Campinas: Editora da Unicamp, 1997. 
PÊCHEUX, MICHEL. Semântica e discurso: uma crítica à afirmação do óbvio. Trad. de Eni P. Orlandi et al. Campinas: Unicamp, 2009.

PRADO, M. Enem de novo: sim ou não. IG: Último segundo, 10 de nov. 2010. Disponível em: <http://ultimosegundo.ig.com.br/colunistas/mateusprado>. Acesso em: 29 out. 2011.

RANCIÈRE, J. O desentendimento. Trad. Ângela L.Lopes. São Paulo: Editora 34, 1996.

SCHREIBER DA SILVA, S. M. Acontecimento discursivo, interdiscurso e memorável na relação entre línguas. In: SEAD - Seminário de Estudos em ANálise do Discurso, IV, nov. de 2009. UFRGS. Resumo. Porto Alegre: CAPES/IL/PPGL/ UFRGS, 2009. CD ROM, p. 1.

SERIOT, P. II Jornada Internacional Patrick Seriot: a língua, a nação, o discurso sobre a língua na URSS e política de Língua, na UFSCar, de 9 a 11 de fevereiro de 2011.

SCHREIBER DA SILVA, S. M. O político na Semântica Histórica da Enunciaçāo e Análise do discurso: argumentação e política de línguas. Inédito, 2004.

SCHREIBER DA SILVA, S. M. O memorável na relação entre a língua francesa e a karipuna. 2011. No prelo. 